
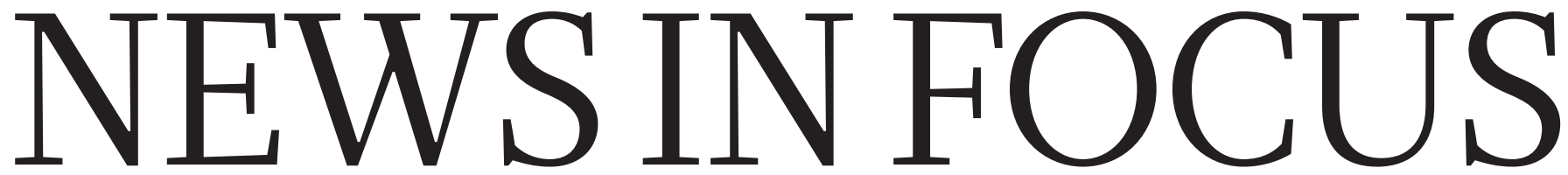

CLIMATE Water will be scarce

in warmer world, huge study says p.10
Phrsics With \$50 million spent, $\mathrm{X}$-ray source is now out in the cold $p .11$
2014 Transgenic monkeys, comets and more will make the news this year $\mathbf{p . 1 3}$
EPIGENETICS A scientist's bid to track down the roots of aggression $\mathbf{p} .14$

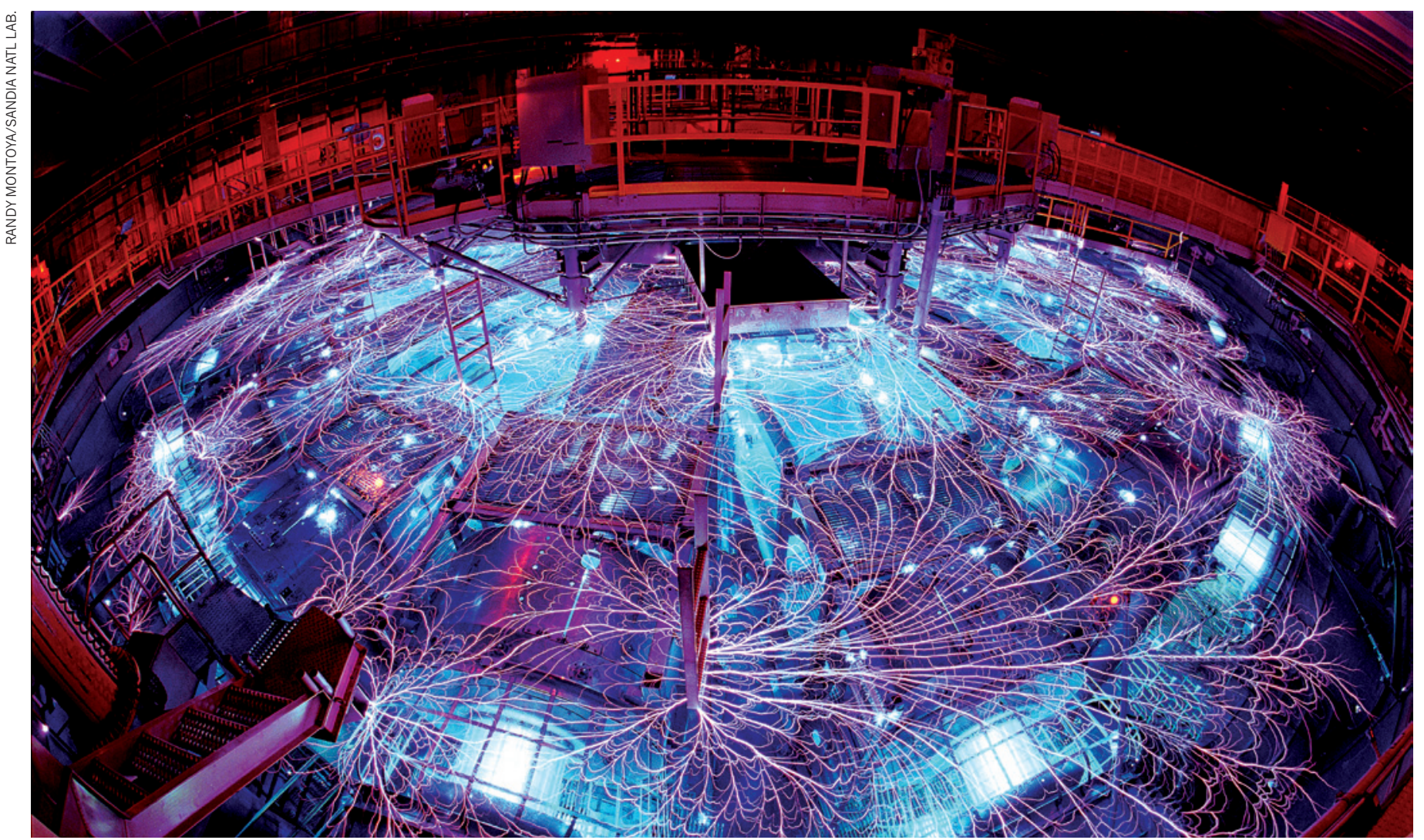

The intense electrical discharge of the $\mathbf{Z}$ machine at Sandia National Laboratories in New Mexico is used in attempts to trigger nuclear fusion.

\title{
PLASMA PHYSICS
}

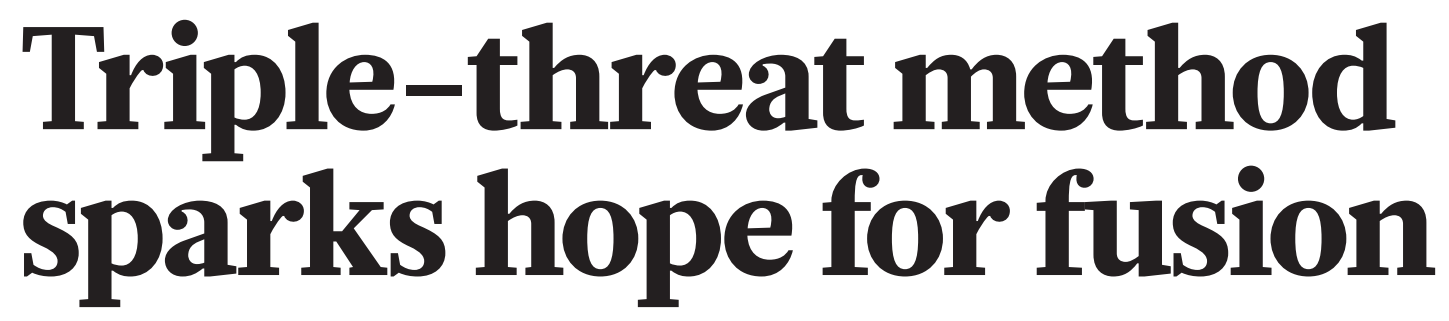

The secrets to its success are lasers, magnets and a big pinch.

BY W. WAYT GIBBS

\section{$\mathrm{T}$}

The $\mathrm{Z}$ machine at Sandia National Laboratories in New Mexico discharges the most intense pulses of electrical current on Earth. Millions of amperes can be sent towards a metallic cylinder the size of a pencil eraser, inducing a magnetic field that creates a force - called a $\mathrm{Z}$ pinch - that crushes the cylinder in a fraction of a second.
Since 2012, scientists have used the $\mathrm{Z}$ pinch to implode cylinders filled with hydrogen isotopes in the hope of achieving the extreme temperatures and pressures needed for energygenerating nuclear fusion. Despite their efforts, they have never succeeded in reaching ignition - the point at which the energy gained from fusion is greater than the energy put in.

But after tacking on two more components, physicists think they are at last on the right path.
Researchers working on Sandia's Magnetized Liner Inertial Fusion (MagLIF) experiment added a secondary magnetic field to thermally insulate the hydrogen fuel, and a laser to preheat it (see 'Feeling the pinch'). In late November, they tested the system for the first time, using 16 million amperes of current, a 10-tesla magnetic field and 2 kilojoules of energy from a green laser.

"We were excited by the results," says 
- Mark Herrmann, director of the $\mathrm{Z}$ machine and the pulsed-power science centre at Sandia. "We look at it as confirmation that it is working like we think it should."

The experiment yielded about $10^{10}$ highenergy neutrons, a measure of the number of fusion reactions achieved. This is a record for MagLIF, although it still falls well short of ignition. Nevertheless, the test demonstrates the appeal of such pulsed-power approaches to fusion. "A substantial gain is more likely to be achieved at an early date with pulsed power," says nuclear physicist David Hammer of Cornell University in Ithaca, New York, who co-wrote a 2013 US National Research Council assessment of approaches to fusion energy.

With its relatively slim US $\$ 5$-million annual budget, MagLIF is a David next to two fusion Goliaths: the \$3.5-billion National Ignition Facility (NIF) at Lawrence Livermore National Laboratory in California, and the $€ 15$-billion (US\$20-billion) ITER experiment under construction in France. (Sandia has about $\$ 80$ million to operate the $\mathrm{Z}$ machine each year, but it serves other experiments in addition to MagLIF.) The NIF squashes fuel capsules using nearly 2 megajoules of laser energy, and ITER will use 10,000 tonnes of superconducting magnets in a doughnut-shaped 'tokamak' to hold a plasma in place to coax self-sustaining fusion.

Both of the big projects have run into problems. After a concerted two-year effort, NIF fell well short of achieving ignition by a 2012 deadline. Its fusion yields have since increased

\section{FEELING THE PINCH}

Magnetized Liner Inertial Fusion uses a heating laser, a stabilizing magnetic field and a force called a Z pinch to implode a cylinder of hydrogen fuel.

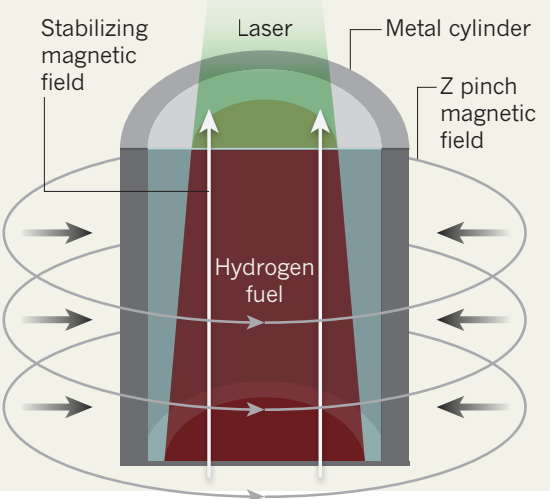

markedly - nearly $10^{16}$ neutrons were created in a recent shot, Herrmann says - but the more than \$300-million-a-year programme faces further budget cuts in 2014. Meanwhile, delays and budget overruns have become the norm at ITER. The facility is not expected to begin operations until $2027-11$ years later than initially planned.

In addition to being cheaper, MagLIF seems to have technical advantages. The laser not only preheats the hydrogen fuel, but also makes it more conductive - and thereby more susceptible to the Z pinch. Furthermore, in a paper published late last year, MagLIF physicists showed evidence suggesting that the applied secondary magnetic field, as well as insulating the fuel, may have the happy side effect of stabilizing the cylinder as it implodes (T. J. Awe et al. Phys. Rev. Lett. 111, 235005; 2013). If so, that would cut down on hydrodynamic instabilities, which can disperse the energy and fuel before fusion can get going, says Stephen Slutz, a Sandia physicist who proposed the MagLIF system in 2009.

In the next few years, MagLIF scientists plan to turn up all three dials at their disposal. They can boost the $\mathrm{Z}$ machine to up to 27 million amperes; they can ramp up the magnetic field to as high as 30 tesla; and they plan to upgrade the laser to 8 kilojoules. They also aim to switch from fuel made of the hydrogen isotope deuterium to fuel containing both deuterium and another isotope, tritium - which should also lift yields. By 2015, they hope to achieve a yield of $10^{16}$ neutrons, or about 100 kilojoules enough to show that ignition is within reach.

It could be crucial to make progress quickly. The US National Nuclear Security Administration, the division of the Department of Energy that funds the NIF, the $\mathrm{Z}$ machine and other laser fusion efforts, plans to deliver an assessment to Congress in 2015 about the future of these technologies. If MagLIF hits its 100-kilojoule goal, it could bolster an argument for upgrading the $\mathrm{Z}$ machine to 60 million amperes or more, which simulations suggest would be sufficient to reach ignition.

"We're all hoping that they will, in fact, find success with their early shots to justify the construction of a larger machine," says Hammer.

\section{Water risk as world warms}

\section{First comprehensive global-impact project shows that water scarcity is a major worry.}

\section{BY QUIRIN SCHIERMEIER}

$\mathrm{W}$ Then pondering the best way to study the impact of climate change, researcher Hans Joachim Schellnhuber liked to recall an old Hindu fable. Six men, all blind but thirsty for knowledge, examine an elephant. One fumbles the pachyderm's sturdy side, while others grasp at its tusk, trunk, knee, ear or tail. In the end, all are completely misled as to the nature of the beast.

The analogy worked. Although many researchers had modelled various aspects of the global-warming elephant, there had been no comprehensive assessment of what warming will really mean for human societies and vital natural resources. But that changed last year when Schellnhuber, director of the Potsdam Institute for Climate Impact Research in Germany, and other leading climate-impact researchers launched the Inter-Sectoral Impact Model Intercomparison Project. This aims to produce a set of harmonized global-impact reports based on the same set of climate data, which will for the first time allow models to be directly compared. Last month it published its initial results in four reports in Proceedings of the National Academy "We are facing
problems
that result
in domestic
instability and
migration." of Sciences ${ }^{1-4}$. These suggest that even modest climate change might drastically affect the living conditions of billions of people, whether through water scarcity, crop shortages or extremes of weather.

The group warns that water is the biggest worry. If the world warms by just $2{ }^{\circ} \mathrm{C}$ above the present level, which now seems all but unavoidable by 2100 , up to one-fifth of the global population could suffer severe shortages.

"Water and all that relies on it, from food to sanitation and public health, is an emblematic aspect of climate change whose urgency people tend to instantly understand," says Schellnhuber.

To assess what a warmer world might mean for the human race, 30 groups from 12 countries have run thousands of simulations, using a standardized set of scenarios for greenhousegas emissions. They made projections of future water availability from a set of global hydrological models in conjunction with five state-of-theart climate models ${ }^{1}$ that combined projections of changes in temperature and precipitation with data on variables such as regional water cycles, river run-off and population.

The multi-model assessment suggests that, in vulnerable regions, climate change will significantly add to the problem of water scarcity 